\title{
Review of the Effects of Grapevine Smoke Exposure and Technologies to Assess Smoke Contamination and Taint in Grapes and Wine
}

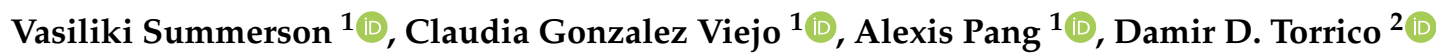 \\ and Sigfredo Fuentes $1, *(\mathbb{D})$
}

1 Digital Agriculture, Food and Wine Group, School of Agriculture and Food, Faculty of Veterinary and Agricultural Sciences, The University of Melbourne, Building 142, Parkville, VIC 3010, Australia; vsummerson@student.unimelb.edu.au (V.S.); cgonzalez2@unimelb.edu.au (C.G.V.); alexis.pang@unimelb.edu.au (A.P.)

2 Department of Wine, Food and Molecular Biosciences, Faculty of Agriculture and Life Sciences, Lincoln University, Lincoln 7647, New Zealand; Damir.Torrico@lincoln.ac.nz

* Correspondence: sfuentes@unimelb.edu.au

check for updates

Citation: Summerson, V.; Gonzalez Viejo, C.; Pang, A.; Torrico, D.D.; Fuentes, S. Review of the Effects of Grapevine Smoke Exposure and Technologies to Assess Smoke Contamination and Taint in Grapes and Wine. Beverages 2021, 7, 7. https://doi.org/10.3390/ beverages7010007

Received: 16 December 2020

Accepted: 21 January 2021

Published: 25 January 2021

Publisher's Note: MDPI stays neutral with regard to jurisdictional claims in published maps and institutional affiliations.

Copyright: (c) 2021 by the authors. Licensee MDPI, Basel, Switzerland. This article is an open access article distributed under the terms and conditions of the Creative Commons Attribution (CC BY) license (https:// creativecommons.org/licenses/by/ $4.0 /)$.
Abstract: Grapevine smoke exposure and the subsequent development of smoke taint in wine has resulted in significant financial losses for grape growers and winemakers throughout the world. Smoke taint is characterized by objectional smoky aromas such as "ashy", "burning rubber", and "smoked meats", resulting in wine that is unpalatable and hence unprofitable. Unfortunately, current climate change models predict a broadening of the window in which bushfires may occur and a rise in bushfire occurrences and severity in major wine growing regions such as Australia, Mediterranean Europe, North and South America, and South Africa. As such, grapevine smoke exposure and smoke taint in wine are increasing problems for growers and winemakers worldwide. Current recommendations for growers concerned that their grapevines have been exposed to smoke are to conduct pre-harvest mini-ferments for sensory assessment and send samples to a commercial laboratory to quantify levels of smoke-derived volatiles in the wine. Significant novel research is being conducted using spectroscopic techniques coupled with machine learning modeling to assess grapevine smoke contamination and taint in grapes and wine, offering growers and winemakers additional tools to monitor grapevine smoke exposure and taint rapidly and non-destructively in grapes and wine.

Keywords: climate change; machine learning; volatile phenols; winemaking; smoke taint

\section{Introduction}

Bushfires are a common occurrence globally, in places such as Australia, South Africa, Mediterranean Europe, and North and South America [1-6]. Unfortunately, climate change effects, such as increases in temperature, winds, and drought, have led to more favorable bushfire conditions [7-13]. Recent climate research predicts an increase of $15-70 \%$ in the number of days of "very high" or "extreme" fire danger by 2050 and a lengthening of the fire season, resulting in more frequent and intense bushfires [12-16].

Many vineyards are located in regions characterized by Mediterranean-type environments with long, hot, dry summers and where both planned controlled burns and unplanned bushfires are prevalent [17-20]. While fires may damage vineyards directly, there is also significant indirect damage caused by smoke drifting into vineyards resulting in grapevine smoke exposure [19]. Grapevine smoke exposure alters the chemical composition of grape berries, and the resulting wine produced is characterized by off-putting smoky aromas such as "burnt wood", "ashy", "burning rubber", and "smoked meat" [1,21-23]. These smoky characteristics have been attributed to various volatile phenols present in smoke, including guaiacol, 4-methylguaiacol, syringols, and cresols [1,4]. While some of 
these compounds may be produced naturally in some grapevine cultivars, elevated levels result in objectional smoky-related aromas [3,24-27]. Unfortunately, the most sensitive period for grapevine smoke exposure also corresponds with the highest risk of bushfires occurring, and with the number of bushfires predicted to rise, the incidence of grapevine smoke exposure and smoke taint development in wine will also most likely increase [28].

Aroma is an important characteristic for wine quality assessment; hence, grapevine smoke exposure and the resulting smoky aromas and flavors associated with smoke taint in wine have led to considerable economic losses due to both discarded fruit that may be contaminated and unsold wine $[3,26,29,30]$. The financial impact of smoke exposure is estimated by the percentage of grapes and/or wine damaged by smoke, which is influenced by several factors such as the vineyard's distance to the fire and prevalent wind direction [31]. It is estimated that the 2006/2007 bushfires in Victoria resulted in approximately AUD 75-90 billion in lost revenue, and the 2009 Black Saturday bushfires resulted in a loss of approximately AUD 300 million to the local wine industry [19,30,32]. Furthermore, the 2019/2020 bushfires in eastern Australia have been estimated to have cost the wine industry AUD 40 million due to smoke taint, burnt vineyards, and lost sales [33]. Thus, grapevine smoke contamination and smoke taint in wine is a significant economic problem.

\section{Composition of Smoke from Bushfires}

Smoke contains many gases such as nitrogen dioxide $\left(\mathrm{NO}_{2}\right)$, methane $\left(\mathrm{CH}_{4}\right)$, carbon dioxide $\left(\mathrm{CO}_{2}\right)$, carbon monoxide $(\mathrm{CO})$, sulfur dioxide $\left(\mathrm{SO}_{2}\right)$, and ozone $\left(\mathrm{O}_{3}\right)$, as well as particulate matter including ash, tar, and liquid droplets [21,34,35]. In addition to this, the pyrolysis of lignin during a bushfire releases numerous volatile phenols, including guaiacol, 4-methylguaiacol, syringol, 4-ethylphenol, eugenol, 4-methylsyringol, and $p$-, $m$ - and $o$-cresols $[1,18,25,36]$. The chemical composition of smoke is greatly influenced by the pyrolytic conditions and the type of fuel present [34]. Lignin is composed of three monolingual subunits: $p$-coumaryl alcohol, coniferyl alcohol, and sinapyl alcohol, which can decompose to produce various volatile phenols $[10,18]$. The ratio of these monolingual subunits varies depending on the plant species; hence the combination of volatiles released from lignin pyrolysis will vary depending on the type of vegetation present $[18,37]$. The combustion temperature and oxygen availability also play an important role in releasing volatile phenolic compounds from lignin degradation [18,34]. The pyrolysis of lignin is said to begin between $280-290^{\circ} \mathrm{C}$; however, as temperatures increase, the composition of lignin pyrolysis products varies, and the release of volatile phenols peaks between $559-650{ }^{\circ} \mathrm{C}$ [18]. Furthermore, different woods vary in their lignin content, with Eucalyptus and Acacia vegetation species typically found in vegetation areas surrounding Australian vineyards containing high amounts of lignin [38]. Regardless of the fuel type, guaiacol and 4-methylguaiacol have been found to represent approximately $20 \%$ of the volatile phenolic compounds present in smoke [39]. Kelly et al. [18] investigated smoke-derived volatile phenol concentrations in wine resulting from five different types of fuels with varying lignin compositions and found that guaiacol and 4-methylguaiacol represented approximately $20 \%$ of total phenols in wine for all fuel sources.

\subsection{Volatile Organic Compounds Responsible for Smoke Taint Aromas and Detection Thresholds}

It has been demonstrated that grapevine smoke exposure changes the chemical composition of grape berries, and wine produced from these berries possesses objectional smoky aromas such as "burnt wood", "ashy", and "smoked bacon" [11,16,26]. These aromas are thought to be derived primarily from phenolic compounds present in smoke (Figure 1), particularly guaiacol and 4-methylguaiacol, which are thought to exhibit "smoky", "burnt wood", "musty", and "phenolic" aromas [11,34]. Table 1 lists some of the smoke-derived volatile phenols found in smoke tainted wines and their associated aromas. 


\section{Volatile phenols in smoke}<smiles>Cc1cccc(O)c1</smiles><smiles>Cc1ccccc1O</smiles><smiles>COc1cc(C)ccc1O</smiles><smiles>COc1ccccc1O</smiles><smiles>COc1cccc(OC)c1O</smiles>

Figure 1. Chemical structures of some volatile phenols present in smoke [11,40-42].

Table 1. Aromas associated with certain volatile phenols present in smoke $[11,36]$.

\begin{tabular}{cc}
\hline Compound & Aromas \\
\hline Guaiacol & Smoky, phenolic, woody, musty/dusty, petroleum-like, sweet, sharp \\
4-methylguaiacol & smoky, toasted, ash, vanilla-like, sweet, phenolic, sharp \\
m-cresol & smoky, petroleum-like, woody, musty/dusty \\
$o$-cresol & smoky, woody, musty/dusty, acrid, pungent, petroleum-like \\
Eugenol & Smoky, musty/dusty, woody, earthy, clove, vanilla-like, phenolic \\
Thymol & Smoky, woody, musty/dusty, cedar, petroleum-like, pungent \\
4-ethylguaiacol & Smoky, woody, ashy, burnt, spicy, clove-like, sweet, cedar, \\
4-ethylphenol & musty/dusty, acrid, pungent \\
Clove, vanilla-like, phenolic
\end{tabular}

Guaiacol and 4-methylguaiacol have been found in wines matured in oak barrels at levels ranging between $10-100 \mu \mathrm{g} \mathrm{L}^{-1}$ and $1-20 \mu \mathrm{g} \mathrm{L}^{-1}$, respectively $[20,34,43]$. They reportedly add complexity to wine flavor at low levels, producing desirable aromas such as "vanilla" and "oak" [26,44]. High concentrations of volatile phenols appear to produce undesirable smoky aromas; however, the minimum amount required to be able to detect these aromas varies depending on the wine [6,34]. According to Simos [44], the structure/body of the wine strongly influences its susceptibility to smoky aromas; for example, 
in delicate sparkling white wines, winemakers have observed smoky characters with levels of guaiacol as low as 6-10 $\mathrm{gg} \mathrm{L}^{-1}$, while in medium-bodied red wines, thresholds range between $15-25 \mu \mathrm{g} \mathrm{L}^{-1}$, and in fuller-bodied Shiraz styles, the threshold range is much higher at $30-40 \mu \mathrm{g} \mathrm{L}^{-1}$ [44]. Table 2 lists some of the volatile phenols present in smoke and their aroma detection thresholds for water, model wine, white wine, and red wine. More recent studies have found that combinations of volatile phenols may be responsible for smoky aromas, including cresols $(o-, p$ - and $m$-cresol), syringol, and phenol $[1,45]$. Furthermore, while each volatile phenol has a distinctive sensory threshold for a particular wine, a synergistic effect is predicted to occur in which combinations of volatile phenols below their corresponding sensory threshold concentrations have noticeable effects on sensory characteristics [1,46]. Kennison et al. [3] found that the blending to produce sub-threshold levels of guaiacol and 4-methylguaiacol did not remedy smoke-tainted wine, as smoky aromas were still perceivable. This shows that several volatile phenols may be involved in the development of smoke taint in wine, and a synergistic effect may be occurring where smoky characteristics may be perceivable despite concentrations of volatile phenols being below the detection thresholds [1,34]. Wang and Chambers [36] also noted that the sensory characteristics of molecules are modified as their concentrations change. It was found that while the odor characteristics generally increased as the concentration increased, the odor character of some compounds also changed. For example, 2,4-dimethylphenol only exhibited the smoky attribute at 1 and $10 \mathrm{ppm}$; however, at $100 \mathrm{ppm}$, it exhibited the musty/dust attribute, and at $1000 \mathrm{ppm}$, it exhibited smoky, woody, and musty/dusty attributes. It is also possible that different combinations of volatile phenols may also result in different smoky aromas, which may also differ from the aromas imparted by the individual molecules [47]. Thus, different concentrations and combinations of volatile phenols may have a different effect on the sensory properties of the resulting wine following smoke exposure [36].

Table 2. Aroma detection thresholds for guaiacol, 4-methylguaiacol, 4-ethylguaiacol, and 4ethylphenol $[3,34,48,49]$.

\begin{tabular}{ccccc}
\hline \multirow{2}{*}{ Compound } & \multicolumn{4}{c}{ Aroma Detection Threshold $\left(\mu \mathrm{g} \mathrm{L}^{-\mathbf{1}}\right)$} \\
\cline { 2 - 5 } & Water & Model Wine & White Wine & Red Wine \\
\hline Guaiacol & $0.48-5.5$ & 20 & $20-95$ & 75 \\
4-methylguaiacol & 10 & 30 & 65 & 65 \\
4-ethylguaiacol & 25 & 47 & 70 & $110-150$ \\
4-ethylphenol & 130 & 440 & 1100 & $605-1200$ \\
\hline
\end{tabular}

\subsection{Uptake and Accumulation of Smoke Volatiles into Grapevines and Grapes}

During a fire event, particulate matter, gases, and volatile phenols from smoke mix with air currents and are transported into the vineyard. The amount of smoke contamination is a function of wind vectors, land topography, temperature gradients, and vineyards' proximity to the fire [44]. Once volatile phenols enter leaves and berries, they are rapidly metabolized into stable glycosidic forms $[24,39,50]$. These glycoconjugate precursors are hydrolyzed during fermentation, releasing them into their volatile forms, where they can impart their aromas into the resulting wine [23,51]. Smoke-derived volatile phenols may enter grapevines via three potential pathways: (i) directly into the berry via diffusion through the waxy cuticle, (ii) uptake into the leaves, and (iii) absorption by the root system after volatile phenols are washed into the soil $[19,31,52]$.

\subsection{Entry and Location of Smoke Volatiles in Grape Berries}

It is believed that the primary point of entry for volatile smoke compounds into berries is by diffusion through the cuticle [18,24,52]. Kennison et al. [3] found that volatile phenols were able to penetrate the cuticle and enter the grape berry. In their study, four types of wine were produced using Verdelho grapes: (1) "unsmoked free-run wine" using the 
free-run juice of control (unsmoked) grapes, (2) "smoked free-run wine" made using the free-run juice of grapes that had been smoked, (3) "unsmoked free-run on skins wine" where the free-run juice from control grapes was fermented on skins, and (4) "smoked free-run on skins wine" made from the free-run juice of smoked wines that were fermented on skins. To produce both types of smoked wines, harvested grape bunches were placed in a custom-built smokehouse and exposed to smoke generated from the combustion of straw for one hour. It was found that both "smoked free-run wine" and "smoked free-run on skins wine" contained high amounts of guaiacol and 4-methylguaiacol, while neither volatile phenol was detected in the two types of unsmoked wines. In addition to this, trained panelists were able to differentiate between smoked and unsmoked wines correctly. This shows that volatile phenols are, therefore, able to penetrate the berry cuticle and enter grapes. Further work by Kennison [47] found that the wax bloom on the grape surface acts as a protective shield, preventing the penetration of smoke compounds. In that study, the wax bloom was removed with chloroform, and grapes were then exposed to smoke. Grapes that had the wax bloom removed had an enhanced guaiacol uptake compared to waxed berries [47].

The Australian Wine Research Institute (AWRI) conducted some of the earliest research into where volatile smoke compounds accumulate in the berries. Initial studies looked at the effects of various "vineyard-washing" treatments in reducing the levels of volatile smoke compounds in grapes and wine [53]. These treatments included washing with cold water, cold water plus a wetting agent, warm water (approximately $25^{\circ} \mathrm{C}$ when in contact with berries), $5 \%$ ethanol, $95 \%$ ethanol, and milk. It was found that none of the washing treatments reduced the levels of volatile phenols in smoke-exposed berries. To determine the location of smoke compounds in grape berries, berry samples were peeled, and the skin and pulp were individually analyzed. Guaiacol and 4-methylguaiacol were detected only in the skins and not in the berries' pulp, showing that smoke compounds entered the grapes' skin; however, they did not permeate the pulp [53].

On the other hand, some studies have demonstrated that smoke compounds are not confined to the skin. Additional research by Hayasaka et al. [2] investigated the location of guaiacol glycosides in grape berries. They found that guaiacol glycosides were nonspecifically distributed throughout the grapes' skin and pulp, unlike previous results for free guaiacol. This suggests that once guaiacol enters grapes' skin, it is glycosylated and then evenly distributed throughout the skin and pulp [2]. Kennison et al. [3] found that wine made using the free-run juice of grapes that had been smoked contained higher concentrations of guaiacol and 4-methylguaiacol than wine produced from the free-run juice of smoked wines that were fermented on skins. If smoke compounds were located solely in grapes' skin, then it would be assumed that the smoked free-run on skins wine would contain higher levels of guaiacol and 4-methylguaiacol [3]. The fact that the smoked free-run wine contained the highest levels of smoke compounds suggests that guaiacol and 4-methylguaiacol glycosylates were stored in both the skin and flesh and that these glycosylated precursors were released into the wine during fermentation [3,26]. Lastly, Sheppard et al. [20] found a negative correlation between skin thickness and guaiacol and 4-methylguaiacol concentrations. Their results showed that the thicker-skinned grapes absorbed less guaiacol and 4-methylguaiacol than thinner skinned grapes. Ultimately, it is believed that volatile phenols accumulate primarily in grape berries' skin and to a lesser extent in the pulp and seeds $[2,5,18,41,53]$.

\subsection{Entry Through Leaves}

Volatile phenols from smoke may enter leaves through the stomata or via the leaf cuticle $[44,54]$. Some studies have shown that the application of aqueous oak extracts to leaves increases oak-derived lactones in wine. This shows that leaves can absorb volatiles, which are then translocated to berries and released into wine during fermentation [50,51,55-57]. Pardo-Garcia et al. [51] found elevated guaiacol levels in berries twenty and thirty-six days after foliar application of aqueous guaiacol solution. Guaiacol glycoconjugates were also 
detected in berries and leaves, further highlighting that volatiles may be absorbed by leaves and translocated to berries. Furthermore, Hayasaka et al. [2] investigated the formation of guaiacol glycoconjugates in berries and leaves of potted Cabernet Sauvignon grapevines using stable isotope tracers and high-performance liquid chromatography-mass spectroscopy (HPLC-MS) and MS-MS/analysis. Leaves and berries were placed in contact with an aqueous mixture of $\mathrm{d}_{0}$ - and $\mathrm{d}_{3}$-guaiacol and then screened for guaiacol glycoconjugates. It was found that guaiacol glycoconjugates were translocated from leaf to leaf, berry bunch to berry bunch, or leaf to berry bunch, but only to a very limited extent. However, these studies involve applying aqueous treatments to leaves, and further research is required to assess the effect of smoke treatments that would occur during a fire.

A positive and statistically significant correlation has been found between the levels of smoke compounds detected in leaves and wine [47]. Leaf samples were taken from grapevines at varying phenological stages that had been exposed to smoke, and levels of guaiacol and 4-methylguaiacol were measured [47]. The highest levels of smoke compounds were found in leaf samples from smoke applications at 7 days post-veraison and harvest, coinciding with peak fire periods [28], while lower levels were detected at the earlier phenological stage when berries were at pea-size. Guaiacol and 4-methylguaiacol were not detected in leaves of grapevines not exposed to smoke. Similar observations were found in wine samples; however, levels of smoke compounds were lower in wine than in leaves from corresponding smoke treatments [47]. A positive correlation $(\mathrm{r}=0.95)$ was found between the guaiacol level in leaves and wine. The concentration of 4-methylguaiacol in leaves also demonstrated a positive correlation $(r=0.86)$ to levels detected in wine. Therefore, the leaves' assessment may provide a potential sign of grapevine smoke exposure and the level of smoke compounds in wine [47].

A further study by Kelly et al. [18] found that a larger leaf area and denser canopies resulted in lower amounts of smoke-derived volatiles in wine. It was suggested that a denser canopy might intercept particulate emissions from bushfires, thereby reducing contact with berries and minimizing the absorption of volatiles. Furthermore, while leaves have been found to accumulate volatile smoke compounds, translocation into berries is slow and may play a minimal role in smoke taint. However, as leaves have been found to contain high levels of guaiacol and 4-methylguaiacol, they may be an additional source of contamination during the winemaking process [47]. Higher levels of guaiacol have been found in must samples that had been macerated with leaves than those without $[47,58]$. Therefore, it is recommended that grapes be hand-harvested following a fire event to avoid the presence of leaves with the fruit [58]. In addition to this, leaf plucking is also recommended to avoid contact of grapes with contaminated leaves and to prevent the addition of leaves during winemaking $[47,58]$.

\subsection{Uptake Through Roots}

A third possible entry point for smoke-derived volatiles into grapevines is via uptake through the root system. As guaiacol is water-soluble and other compounds such as cresols and syringols are slightly water-soluble, rainfall following a bushfire may wash smoke compounds into the soil, where they may be absorbed by the roots of grapevines and translocated to the berries [31]. Entry through this pathway is unlikely to occur, as the casparian strip in roots may inhibit volatiles' absorption. Secondly, there is little to no rainfall during the times bushfires are prevalent $[19,31]$. Further research is required to investigate whether volatile phenols' uptake through the root system contributes to smoke.

3. Influence of Vine Phenology, Grapevine Cultivar, and Duration of Smoke Exposure on Smoke Taint Development

\subsection{Influence of Vine Phenology and Duration of Smoke Exposure}

The timing and duration of smoke exposure greatly influence the extent of volatile phenol uptake by grapevines and, hence, the level of smoke taint in wine $[4,29]$. The most sensitive period for smoke contamination in grapevines is seven days post-veraison [28,31,32,34,59], 
which unfortunately coincides with bushfires' highest risk of occluding [28]. Studies have demonstrated that exposure of grapevines to smoke during this period results in the highest concentrations of volatile smoke compounds accumulating in grape berries and, hence, the greatest severity of smoke taint in wine [34,59]. Table 3 lists the growth stages of grapevines and the sensitivity to smoke exposure. As is expected, it has also been found that prolonged or repeated exposure of grapevines to smoke further increases the levels of volatile smoke compounds in grapes and wine [34].

Table 3. Grapevine growth stage and the sensitivity to smoke exposure $[8,60]$.

\begin{tabular}{ccc}
\hline Period & Growth Stage & Smoke Uptake Risk \\
\hline P1 & $\begin{array}{c}\text { 10-cm long shoots } \\
\text { Flowering }\end{array}$ & Low \\
& Low \\
\hline P2 & $\begin{array}{c}\text { Pea-sized grape berries } \\
\text { Onset of bunch closure }\end{array}$ & Variable (low to medium) \\
& Start of veraison to 3 days after onset & Variable (low to medium) \\
P3 & 7 days post-veraison to harvest & High \\
\hline
\end{tabular}

Abbreviations: P1 = Period 1: the stages between "10-cm shoots" to "full bloom", P2 = period two: the stages between "berries of pea-size" to "the onset of veraison", P3 = period 3: the period between 7 days post-veraison and harvest.

Kennison et al. [34] examined the effects of timing and duration of smoke exposure on the chemical composition and sensory properties of wine. Smoke was applied to Merlot grapevines at different phenological stages (veraison 3, 7, 10, 15, 18, 21, or 24 days post-veraison) for either a single $30 \mathrm{~min}$ period or eight consecutive exposures, with each lasting $30 \mathrm{~min}$. In the experiments involving a single smoke application, guaiacol levels, 4-methylguaiacol, 4-ethylphenol, and 4-ethylguaiacol were the highest in wine produced from grapes smoked 7 days post-veraison. Additionally, the highest levels of smoke taint markers were observed in wines produced from grapes repeatedly exposed to smoke. These wines contained at least a four-fold increase in volatile phenols compared to wines produced from grapes that received a single smoke exposure. Sensory studies also showed that wines produced from repeatedly smoked grapevines received higher scores for smoky aromas, including "burnt rubber", "smoked meat", "leather", and "disinfectant" and "hospital" [47], while wine made from grapes exposed to a single smoke exposure varied in their sensory properties depending on the timing of the smoke exposure. The highest intensities of smoky aromas ("burnt rubber", "smoked meat", "leather", "disinfectant", and "hospital") were found to occur in wines produced from grapes exposed to a single smoke exposure at seven or ten days post-veraison, which is in accordance with the highest levels of guaiacol and 4-methylguaiacol. This study found that the timing of smoke exposure can influence the composition and sensory properties of wine, with the most sensitive period being seven days post-veraison. Furthermore, repeated smoke exposure over the post-veraison period may have a cumulative effect on volatile phenol concentrations [34].

In an additional study, Kennison et al. [59] further investigated the effect that phenological timing of smoke exposure played on the severity of taint in wine. Smoke was applied to field-grown Merlot grapevines at various phenological stages, including P1, the period from "10-cm shoots" to "full bloom"; P2, the stages between "berries of pea-size" to "the onset of veraison"; and P3, the period between 7 days post-veraison and harvest. Again, it was found that smoke taint in wine was most severe when grapevines were exposed to smoke between 7 days post-veraison and harvest (P3) [59]. During this period, grape bunches represent major carbohydrate sinks; therefore, the increased smoke taint may be due to increased translocation from leaves and direct berry uptake [59]. The lowest taint level was found to occur when grapes were exposed to smoke during P1 ("10-cm shoots" to "full bloom"). These wines were characterized by standard wine aromas, including "red berry fruits" and "confection" and were found to contain the lowest levels of smoke-derived volatile phenols [59]. A possible explanation for low levels of taint in 
wine produced from berries exposed to smoke at early stages of development may be because of the small size of the berries and hence less surface area available for the uptake of smoke compounds [20,59] or the lack of fruit during the early stages of development [59]. Furthermore, any smoke compounds absorbed may be diluted in concentration as the grapes grow and expand in size or lost via volatilization or degradation in a similar manner to pesticides [20,59].

\subsection{Influence of Cultivar on Sensory Properties Following Smoke Exposure}

Several studies have shown that following smoke exposure, the concentrations of volatile phenols in grapes and wine vary depending on the grapevine cultivar. Research conducted by the Centre of Expertise in Smoke Taint Research (CESTR) investigated the effect that grape variety and smoking duration have on the levels of free phenols in grapes and wine following [7]. Seven different wine grape varieties were picked and then immediately smoked in a purpose-built chamber that used barley straw to generate smoke. Each variety was smoked for different periods: unsmoked (control), one hour (mediumsmoked), and three hours (high-smoked). Berry and wine samples were then analyzed for levels of free phenols. It was found that increasing the duration of berry smoking led to higher concentrations of free phenols in grapes and wine; however, the level of increase was not proportional to the increase in the time of smoking [7]. Of the seven different grape varieties, Pinot Gris grape samples were the least affected by the smoking duration and had the least amount of increase in free phenols with an increased amount of smoking time, while Shiraz and Merlot were the most affected and had the greatest increase in free phenols with increased duration of smoking. This shows that different grape varieties vary in their susceptibility and uptake of volatile smoke compounds [7], potentially due to differences in berry skin thickness; however, further research is required to determine this. Furthermore, some grape varieties naturally contain low levels of guaiacol and 4methylguaiacol glycosides in fruit and leaves, including Shiraz, Merlot, and Muscat, which may also explain the differences in volatile phenol concentrations [3,24-27]. Low levels of volatile phenolic precursors, including phenol, guaiacol, cresols, syringol, methylsyringol, and eugenol, have been detected in numerous grape varieties and may be derived from the degradation of lignified areas of the berries such as the seed $[27,45]$. The variation in free phenol concentrations due to different smoking durations was less pronounced with the wine samples, indicating that the winemaking process leads to an equalization of free volatile concentrations [7].

Ristic et al. [35] also found that different grape varieties vary in their susceptibility to smoke contamination. In their experiment, smoke was applied to seven different grape cultivars (Chardonnay, Sauvignon Blanc, Pinot Gris, Pinot Noir, Shiraz, Cabernet Sauvignon, and Merlot) for one hour at seven days post-veraison. Low levels of guaiacol glycoconjugates were found in the unsmoked control grapes at levels between $37-81 \mu \mathrm{g} \mathrm{kg}^{-1}$, except for Shiraz grapes, which were found to contain $602 \mu \mathrm{g} \mathrm{kg}^{-1}$. This is in line with the theory that guaiacol glycoconjugates occur naturally in certain grape varieties, particularly Shiraz. Guaiacol glycoconjugates were also detected in control wines produced from unsmoked grapes, with white wines containing up to $10 \mu \mathrm{g} \mathrm{L}^{-1}$, while red wines contained between 19-54 $\mu \mathrm{g} \mathrm{L}^{-1}$ and $334 \mu \mathrm{g} \mathrm{L}^{-1}$. Volatile phenols were not detected in control white wine varieties, and 4-methylguaiacol was not detected in control red wines; however, guaiacol, cresols, and syringol were detected in control red wines. Guaiacol glycoconjugate levels for grapes exposed to smoke ranged from $252 \mu \mathrm{g} \mathrm{kg}{ }^{-1}$ for Pinot Noir to $2452 \mu \mathrm{g} \mathrm{kg} \mathrm{g}^{-1}$ for Merlot, approximately 3-30-fold higher concentrations than control (unsmoked) grapes [35]. For wines produced from smoked grapes, guaiacol glycoconjugate levels ranged from 180-306 $\mu \mathrm{g} \mathrm{L}^{-1}$ for white wines to $111-1480 \mu \mathrm{g} \mathrm{L} \mathrm{L}^{-1}$ for red wines. It is thought that the higher concentration of guaiacol glycoconjugates in red wines compared to white is because of increased skin contact time during fermentation, resulting in greater guaiacol glycoconjugate extraction into the wine [35]. Volatile phenol concentrations were also found to be higher in smoke-affected wines. Pinot Gris contained the highest volatile phenol 
concentrations for the white grape varieties, with $10 \mu \mathrm{g} \mathrm{L}^{-1}$ guaiacol, $8 \mu \mathrm{g} \mathrm{L}{ }^{-1}$ cresols, and $2 \mu \mathrm{g} \mathrm{L}{ }^{-1}$ syringol. Similar levels were found in Pinot Noir with $6 \mu \mathrm{g} / \mathrm{L}$ guaiacol, $8 \mu \mathrm{g} \mathrm{L}^{-1}$ cresols, and $3 \mu \mathrm{g} \mathrm{L}{ }^{-1}$ syringol. Shiraz wine contained the highest concentration of guaiacol at $26 \mu \mathrm{g} \mathrm{L}^{-1}$, while Cabernet Sauvignon contained the highest levels of cresols at $17 \mu \mathrm{g} \mathrm{L}^{-1}$. From the grape glycoconjugate data, it was suggested that Merlot, Shiraz, and Sauvignon Blanc grapes were the most heavily tainted when compared to controls, while volatile phenol data suggests that Cabernet Sauvignon and Merlot wines were most heavily tainted [35].

An investigation into the effect of fruit maturity revealed that the intensity of smoke taint in wine was influenced by berry ripeness; however, results varied for different grape cultivars [25]. Chardonnay, Sauvignon Blanc, Merlot, and Shiraz grapevines were exposed to smoke for one hour at approximately seven days post-veraison. Grapes were then harvested at two different time points: Harvest A when total soluble solids (TSS) was at 16$20^{\circ}$ Brix and Harvest B when TSS was $22-25^{\circ}$ Brix. The lower berry ripeness of Harvest A is typically required for light-bodied or sparkling wines, while the higher maturity of Harvest $\mathrm{B}$ is required for full-bodied wines [25]. Fruit maturity was found to influence the intensity of smoke taint in the resulting wines; however, differences were observed for the different grape varieties. For Sauvignon Blanc, smoke taint aromas were observed in wine produced from early harvested grapes; however, this was the opposite for Chardonnay, in which only wine produced from late-harvested grapes was found to be tainted. For the red wine varieties, both Shiraz and Merlot exhibited smoke taint aromas regardless of fruit maturity; however, the intensity of smoky aromas was higher for Merlot wine produced from early harvested grapes and for Shiraz wine produced from late-harvested grapes. This study's findings showed the difficulties that grape growers and winemakers faced in assessing smoke contamination in grapevines and the resulting smoke taint in wine. Standard practice dictates that grapes should be sampled following grapevine smoke exposure as soon as possible, and small-lot fermentations, as well as sensory and/or chemical analyses, should be conducted. As shown in this study, early testing may lead to false negatives for certain grape varieties as the extent of smoke taint may be underestimated or not detected at all [25]. Therefore, an assessment may need to be conducted on two occasions, at early and late stages, to obtain the full extent of smoke taint development.

\section{Effect of Smoke Exposure on Vine Physiology and Fruit Production, and Carry-Over of Smoke Compounds to Following Years}

While smoke exposure on plant physiology and growth is not completely understood, comparisons can be made with studies on the effects of air pollutants as many of the chemicals present in smoke are also components of air pollution [21,47]. Smoke contains a complex mixture of gases, including $\mathrm{SO}_{2}, \mathrm{CO}_{2}, \mathrm{NO}_{2}$, and $\mathrm{O}_{3}$, which have been shown to inhibit photosynthesis and cause leaf necrosis $[21,35,61]$. Looking at a mixture of three evergreen and three deciduous conifer tree varieties, Calder et al. [61] found that photosynthesis was reduced by more than $50 \%$ following a twenty-minute smoke exposure in five of the six conifer species studied. Evergreen conifers were found to recover faster than deciduous varieties, and no long-term changes were observed in seedling growth or leaf chemistry. Smoke was thought to reduce photosynthetic capacity by reducing stomatal conductance $\left(\mathrm{g}_{\mathrm{s}}\right)$ and impairing biochemical function. In a similar study, the $\mathrm{g}_{\mathrm{s}} \mathrm{CO}_{2}$ assimilation rate and intercellular $\mathrm{CO}_{2}$ levels of Chrysanthemoides monilifera were significantly reduced for $5 \mathrm{~h}$ following $1 \mathrm{~min}$ smoke exposure [62]. Grapevines are reported to be tolerant to several stressors such as drought, high atmospheric vapor pressure deficit, high irradiance, UV-B radiation, and high temperatures [21]. Consequently, their resilience may allow them to withstand short periods of smoke exposure without damaging leaf function [21]. Bell, Stephens, and Moritz [21] found that short periods of smoke exposure to Cabernet Franc, Cabernet Sauvignon, Chardonnay, Durif, Pinot Noir, and Syrah grapevine cultivars had only short-term physiological effects on leaf functioning. All cultivars returned to pre-smoke levels of photosynthesis, $\mathrm{g}_{\mathrm{s}}$, and transpiration within $48 \mathrm{~h}$. 
In other research, Kennison et al. [59] found that exposure to smoke resulted in reduced yields. In the smoke exposure season (year 1), grapevines exposed to smoke produced an average of $11 \mathrm{~kg}$ of fruit per vine, compared to control vines, which produced an average of $15 \mathrm{~kg}$ per vine. In the following season (i.e., year 2), no further smoke exposure occurred; however, yields in grapevines originally exposed to smoke yielded approximately $6.4 \mathrm{~kg}$ less fruit than control. The reduced fruit yield in the year following smoke exposure was thought to result from reduced photosynthetic capacity [59]. In a previous study, Kennison et al. [34] found that smoke exposure reduced sugar accumulation in berries and caused necrotic lesions in leaves, which reduced the photosynthetically active leaf area. It was proposed that smoke exposure led to a reduction in photosynthetic capacity, which inhibits berry maturation and ripening [34]. Therefore, the reduction in fruit yield may result from altered physiological functioning in the grapevine brought about by smoke exposure [59].

Conversely, Ristic et al. [35] found few significant differences in berry growth, maturation, and yield between control and smoke-exposed grapevines. Smoke was applied to seven different grapevine cultivars (Chardonnay, Sauvignon Blanc, Pinot Gris, Pinot Noir, Shiraz, Cabernet Sauvignon, and Merlot) for $1 \mathrm{~h}$ at approximately 7 days post-veraison. Measurements were then conducted to assess the effects on yield, vegetative growth, and vine physiology. Yield was not affected by smoke exposure, and few significant differences were observed between control and smoke-exposed grapes for berry weight and sugar accumulation. Only Shiraz and Pinot Noir grapevines exposed to smoke had lower TSS than control [35]. One factor that did appear to be affected by smoke exposure was stomatal conductance, and responses varied for the different grape varieties [35]. Cabernet Sauvignon, Merlot, Shiraz, Pinot Noir, and Chardonnay displayed significant reductions in $g_{s}$ immediately after smoke exposure. Except in Pinot Noir, the initial reduction in $g_{s}$ was close to $50 \%$ of the controls. There was also variation in the time it took the $g_{s}$ for each grapevine variety to recover. Pinot Noir grapevines recovered the fastest, followed by Chardonnay (within 1-3 days), Shiraz ( $<6$ days), Cabernet Sauvignon ( $6-10$ days), and finally Merlot, which was the most sensitive and took the longest to recover (10-15 days). While Shiraz grapevines regained stomatal control after 6 days, measurements taken 17 days later demonstrated that $\mathrm{g}_{\mathrm{s}}$ was higher in smoked vines than control. This variation in response may be due to Shiraz vines' anisohydric behavior, which allows them to be less responsive to environmental changes [35]. Furthermore, Sauvignon Blanc and Pinot Gris appeared to be unaffected by smoke exposure.

It was not surprising that there was variation in $g_{s}$ between grapevine varieties following smoke exposure, as previous studies have also found varietal differences in response to other stressors such as heat stress and/or water deficit $[35,63,64]$. Calder et al. (2010) also found differences in $\mathrm{g}_{\mathrm{s}}$ recovery time between conifer species following smoke exposure and noted that plant species could develop tolerance to pollutants that affect photosynthesis. Different plant species may employ various fire resistance strategies and develop tolerance mechanisms to avoid smoke exposure's detrimental effects [61]. Fuel type may also influence the physiological response of grapevines to smoke [21]. As smoke composition can differ depending on the fuel sources present, the varying emissions produced may result in different leaf-level responses amongst plants [21]. Bell, Stephens, and Moritz (2013) found grapevines were more sensitive to smoke generated from burning leaf litter from Coast Live Oak compared with Tasmanian Bluegum. This research only used single fuel types; however, results may vary if a mixture of fuel sources are used as occurs in bushfires [21]. Furthermore, the duration of smoke exposure, the concentration of smoke components, and other plant stressors such as nutrient status, drought, and high temperatures may also affect the physiological response and recovery of grapevines following smoke exposure [21,44]. For example, research by Summerson et al. [5] found that the intensity of smoke exposure affected the extent of stomatal closure and hence $g_{s}$ in Cabernet Sauvignon grapevines. Further studies should, therefore, take all variables into account [21]. 
Smoke taint compounds do not appear to carry over to the following season [32,47]. Grapevines repeatedly exposed to smoke in one year have been shown not to carry over volatile phenols and their metabolites into subsequent years, when no further smoke exposure occurred $[47,59]$.

\section{Glycosylation and Hydrolysis of Volatiles into Wine}

Volatile phenols have been found to accumulate in leaves and berries as non-volatile glycoconjugates, with studies suggesting that that glycosylation of smoke-derived volatiles occurs within 10-14 days of smoke exposure $[9,22,23,65]$. In berries, glycoconjugates are located primarily in the skin and pulp of grapes, with skins containing higher proportions by mass than pulp [9]. Glycoconjugates are formed when volatile aglycones are bound to a sugar moiety containing glucose via a $\beta$-glucosidic bond [66]. Using a stable isotope tracer technique combined with HPLC-MS and MS/MS, Hayasaka et al. [2] identified seven different glycoconjugates of guaiacol in grapevine leaves and berries, while in a further study, Hayasaka et al. [45] found that in addition to guaiacol, other volatile phenols also formed glycoconjugates, with glycosides of phenol; $p-, m$ - and $o$-cresols; methylguaiacol; syringol; and methylsyringol having been detected.

During fermentation, non-volatile glycosides may be metabolized by yeasts and enzymes into their free, sensory-active active forms, where they can impart their smoky aromas into the resulting wine $[22,51,65,66]$. A significant amount of the "glycoconjugate pool" remains in the wine, which continues to hydrolyze during storage slowly [4]. Kennison et al. [11] found that the levels of guaiacol, 4-methylguaiacol, 4-ethylguaiacol, 4-ethylphenol, and eugenol increased during the winemaking process, demonstrating that phenolic precursors were present, presumably as glycosides. Trace levels of guaiacol and 4methylguaiacol were detected in the free-run juice from smoked berries, with higher levels detected in the finished wine, indicating hydrolysis glycosidic precursors had occurred. Enzyme ( $\beta$-glucosidase) and acid-catalyzed hydrolysis of glycoconjugate precursors were also investigated. It was found that strong acid hydrolysis ( $\mathrm{pH} 1.0)$ and enzyme hydrolysis by $\beta$-glucosidase was successful at liberating volatile phenols from smoked free-run juice. Mild acid hydrolysis ( $\mathrm{pH}$ 3.2-3.7) was not sufficient at releasing volatile phenols from their glycosidic bound forms. This was further highlighted by Ristic et al. [4], who observed the stability of smoke taint by following changes in the composition and sensory properties of wine after 5 to 6 years of bottle aging. Small increases of up to $6 \mu \mathrm{g} \mathrm{L}^{-1}$ in guaiacol and 4-methylguaiacol were observed after bottle-aging of smoke-affected red and white wines, while syringol levels increased by a considerably higher amount $\left(29 \mu \mathrm{g} \mathrm{L}^{-1}\right)$. However, acid hydrolysis resulted in a significant increase in free volatile phenol concentrations, showing that the glycoconjugates were relatively stable to the mildly acidic conditions of wine [4]. Studies by Singh et al. [26] also found increases in guaiacol and 4-methylguaiacol concentrations in different wines after two years of bottle-aging. Guaiacol concentrations increased by $10-15 \%$ in Sangiovese wines, while in Chardonnay wines, the increase was significant at $200 \%$. Similarly, 4-methylguaiacol concentrations increased by a considerable $300 \%$ in Chardonnay wines, and in Cabernet Sauvignon, they increased by $45-67 \%$. Acid hydrolysis of the wine samples resulted in a several-fold increase in free guaiacol and 4-methylguaiacol levels.

Hydrolysis of glycoconjugates has also been demonstrated to occur in the mouth $[24,67]$. Mayr et al. [67] found that monosaccharide and disaccharide glycosides from smoke-derived volatile phenols were hydrolyzed by enzymes and/or bacteria present in the saliva, and this may have a significant effect on the flavor and aftertaste of wine.

Glycoconjugates remain "hidden" in berries until they are released into their free forms by enzymatic or acid hydrolysis, as they cannot be detected by simple sensory analysis or gas chromatography-mass spectroscopy (GC-MS) $[11,41,43,59]$. Therefore, growers and winemakers must assess for free forms of phenolic marker compounds and glycosidically bound forms to get a proper idea of the extent of smoke contamination and the level of smoke taint development in the resulting wine $[9,11,43]$. Acid hydrolysis of juice samples 
may be used to assess for glycoconjugates levels; alternatively, direct measurements may be conducted, such as through the use of HPLC-MS/MS [9,59].

Ristic et al. [68] evaluated the use of eight different yeast strains for primary fermentation of Grenache wine to assess whether they could alter the intensity of smoke taint in wine. The yeast strains evaluated were: Saccharomyces cerevisiae Lalvin ICV D254, Lalvin ICV GRE, Enoferm BDX (Lallemand Australia), SIHA Aktiv hefe 3 (Begerow, Germany); Saccharomyces uvarum Lalvin S6U (Lallemand, Australia); Saccharomyces bayanus AWRI 1176 (Lallemand, Australia); Saccharomyces cerevisiae x Saccharomyces kudriavzevii AWRI 1503 (Maurivin, Australia); and S. cerevisiae x Saccharomyces cariocanus AWRI Fusion (Maurivin, Australia). It was found that wine fermented with the ICV GRE yeast strain contained significantly less guaiacol $\left(5.3 \mu \mathrm{g} \mathrm{L}^{-1}\right)$ than wine fermented with the $S$. uvarum S6U $\left(12.9 \mu \mathrm{g} \mathrm{L}^{-1}\right)$ strain. It was suggested that the increased guaiacol concentrations in wines fermented with $S$. uvarum S6U might be the result of increased $\beta$-D-glucosidase activity, the enzyme responsible for the hydrolysis of glycosidically bound aroma precursors, or due to an increased yeast population $[22,68]$. Furthermore, some yeast strains' activity is less inhibited by must glucose and $\mathrm{pH}$, resulting in increased glucosidase activity [68,69]. Pectinase activity may also affect guaiacol and glycoconjugate levels in wine as they catalyze the hydrolysis of grape skin pectins, thereby facilitating the release of compounds stored in grape skins [68]. Thus, the selection of certain yeast strains may be used to lessen the hydrolysis and release of volatile phenolic glycosides during fermentation, thereby reducing smoke-related aroma formation [22,68].

It is believed that volatile compounds' glycosylation occurs as a means of detoxification for plants by increasing their water solubility, thereby facilitating transportation and storage and reducing their toxicity $[24,50]$. The glycosylation of xenobiotic molecules in plants is catalyzed by glycosyltransferases (GTs), and recently a resveratrol GT (UGT72B27) was found to be responsible for the formation of smoke-derived phenolic glycosides $[24,41]$. UGT72B27 is highly expressed in grapevine leaves and berries, and it is thought that trans-resveratrol, a naturally occurring secondary metabolite in Vitis vinifera species, is its primary substrate. However, it was found that UGT72B27 displayed high activity for converting smoke-derived volatile phenols into glycosides, in particular guaiacol, 4-methylguaiacol $m$-cresol, and $o$-cresol [24]. It was suggested that knowledge in the expression profile and activity of UGT72B27 could be used in breeding programs to reduce the risk of smoke taint development in wine. By increasing the expression of UGT72B27, it may be possible to enhance the formation of sensory-inactive glycoconjugates, thereby reducing the smoky aromas associated with smoke taint [24]. Additionally, the overexpression of UGT72B27, coupled with yeast strains that possess reduced $\beta$-D-glucosidase during primary fermentation, may further mitigate the development of smoke taint in wine.

\section{Pre- and Postharvest Methods for Reducing Smoke Contamination and Smoke Taint in Wine}

There are several techniques that growers and winemakers can employ both in-field and in the winery to reduce concentrations of smoke-derived volatiles in the final wine and minimize smoke taint development following a fire event. Table 4 lists a number of these techniques, and it is recommended that they be used in combination to ensure minimum levels of smoke-derived volatile phenols and smoky aromas in the final wine [70]. Promising research by van der Hulst et al. [71] and Favell et al. [40] has found that foliar applications of kaolin or biofilm composed from phospholipids may provide some protection from the uptake of smoke compounds. Furthermore, the treatment of wines by activated carbon has also been shown to reduce smoke taint effectively; however, it is not selective and can impact the overall aroma and flavor [72]. 
Table 4. Techniques for reducing smoke taint in wine.

\begin{tabular}{|c|c|c|}
\hline Technique & Details & References \\
\hline $\begin{array}{l}\text { Hand harvest berries and } \\
\text { maintain their integrity }\end{array}$ & $\begin{array}{l}\text { Minimize skin rupturing as long as possible as contact of juice with } \\
\text { skins can lead to higher concentrations of smoke-derived volatile } \\
\text { compounds in the final wine }\end{array}$ & {$[31,44]$} \\
\hline $\begin{array}{l}\text { Avoid the inclusion of leaves in } \\
\text { fruit harvest }\end{array}$ & $\begin{array}{c}\text { Contaminated leaf material may increase levels of volatile phenols, } \\
\text { leading to an increased risk of smoke taint }\end{array}$ & {$[31,44]$} \\
\hline $\begin{array}{l}\text { Plucking leaves and washing } \\
\text { grapevines }\end{array}$ & $\begin{array}{l}\text { Leaf plucking and high-pressure cold-water wash in the vineyard } \\
\text { may remove ash; however, washing the entire canopy may increase } \\
\text { smoke compounds in grapes }\end{array}$ & {$[47,53]$} \\
\hline Cooling fruit & $\begin{array}{l}\text { Processing berries at } 10{ }^{\circ} \mathrm{C} \text { causes less extraction of smoke-derived } \\
\text { compounds compared to processing berries at } 25^{\circ} \mathrm{C}\end{array}$ & {$[31,44]$} \\
\hline Whole bunch press & $\begin{array}{l}\text { Whole bunch processing may minimize the release of volatile } \\
\text { phenols from smoke }\end{array}$ & {$[44,73]$} \\
\hline Separate press fractions & $\begin{array}{l}\text { Fruit cooling may reduce smoky aromas in the first } 400 \mathrm{~L} / \mathrm{t} \text {. Free-run } \\
\text { juice may contain less smoky aromas }\end{array}$ & {$[31,44,73]$} \\
\hline $\begin{array}{l}\text { Conduct trials with fining } \\
\text { agents before fermentation }\end{array}$ & $\begin{array}{l}\text { Variable results have been demonstrated with PVPP and isinglass in } \\
\text { reducing smoke taint characters. Fining with activated carbon has } \\
\text { been effective }\end{array}$ & {$[31,44,72,73]$} \\
\hline Yeast selection & $\begin{array}{c}\text { Yeast selection may affect the levels of smoke compounds in the final } \\
\text { wine and alter smoke-related aromas and flavors }\end{array}$ & {$[31,44,68,73]$} \\
\hline $\begin{array}{l}\text { Keep fermentation time on skins } \\
\text { to a minimum }\end{array}$ & $\begin{array}{l}\text { Minimizing fermentation time on skins has been shown to reduce } \\
\text { smoky aromas and flavors }\end{array}$ & {$[11,44,68]$} \\
\hline The use of oak chips and tannins & $\begin{array}{l}\text { Increases the complexity of wine and may reduce the intensity of } \\
\text { smoky aromas and flavors }\end{array}$ & [68] \\
\hline $\begin{array}{l}\text { Reverse osmosis treatment } \\
\text { of wine }\end{array}$ & $\begin{array}{l}\text { Effective in reducing smoky characteristics; however, overtime } \\
\text { smoky aromas and flavors were found to reappear }\end{array}$ & [29] \\
\hline $\begin{array}{l}\text { Foliar application of kaolin } \\
\text { or biofilm }\end{array}$ & $\begin{array}{l}\text { Foliar applications of kaolin or a biofilm consisting of phospholipids } \\
\text { have been shown to provide some form of protection from volatile } \\
\text { phenol uptake }\end{array}$ & {$[40,71]$} \\
\hline $\begin{array}{l}\text { Market wine for quick sale and } \\
\text { immediate consumption }\end{array}$ & $\begin{array}{l}\text { Smoky characteristics have been found to increase over time as the } \\
\text { wine ages in the bottle }\end{array}$ & {$[4,29,44,73]$} \\
\hline
\end{tabular}

\section{Current and Emerging Methods of Assessing Grapevine Smoke Contamination and Smoke Taint in Wine}

To determine the extent of smoke exposure, the AWRI and the Government of Western Australia: Department of Primary Industries and Regional Development recommend that growers use a combination of analytical techniques to assess the risk of smoke taint development. Samples of grape berries and grape juice should be sent to a commercial laboratory to assess for levels of both free and "bound" smoke taint markers such as guaiacol, 4-methylguaiacol, cresols, and syringols. This will give information about whether grapevines have been exposed to smoke; however, it cannot be used to determine the level of smoke taint in wine as this can be impacted by fruit handling and winemaking techniques [70]. Therefore, it is recommended that small-scale ferments are also conducted in addition to chemical analysis, which will allow for a sensory assessment of wines and further determine the risk of smoke taint development [70,74].

Traditional laboratory-based methods for assessing grapevine smoke contamination and smoke taint in wine can be incredibly time-consuming as growers must take time to harvest samples from different regions of their vineyards and conduct pre-harvest mini ferments for sensory analysis. Furthermore, there may be a delay in receiving results during busy periods when numerous samples from different vineyards require analysis [75]. Current chromatographic techniques such as GC-MS and HPLC are widely used for 
qualitative and quantitative chemical analysis, such as determining levels of free and glycosidically bound volatile phenols in wine; however, they often require time-consuming and destructive sample preparation and can incur significant costs due to expensive reagents and instruments [76]. Consequently, research is being conducted on alternative methods of analysis, and of particular interest are spectroscopic techniques due to their ease of use, rapid results, lack of sample preparation, and non-destructive nature, allowing for repeated measurements [75-79]. The use of infrared (IR) spectroscopy and IR thermography for many agricultural and viticultural applications have increased in recent years, with remote sensing technologies becoming more readily accessible to growers and farmers as the cost for their use decreases and popularity increases [78,80]. In addition to this, the development of smaller handheld spectroscopic devices has greatly increased their portability, making them far easier to use in-field [78].

There has been significant research demonstrating the effectiveness of IR thermography to estimate grapevine water potential [81-84]. When plants transpire, the evaporation of water from the stomata cools leaves; however, when plants are water-stressed, the stomata close, and transpiration ceases, which causes leaf temperatures to elevate. These changes in leaf temperatures can be detected using IR thermography and can be used to predict the water status of various plants such as grapevines [84-86]. Based on this principle, IR thermography has been proposed as a method for detecting grapevine smoke contamination since smoke exposure has been demonstrated to cause stomatal closure and hence elevated leaf temperatures $[28,35,59,63,87,88]$. Research by Fuentes et al. [88] proposed a non-invasive tool for detecting grapevine smoke contamination based on stomatal conductance changes evaluated by IR thermography and machine learning modeling. Further research on the use of IR thermography as a method for grapevine smoke contamination is required, particularly if smoke exposure occurs during periods of drought stress when stomata may be already closed.

Increasing research on NIR spectroscopy coupled with machine learning (ML) modeling has gained significant interest in the food industry [89-92]. A branch of artificial intelligence (AI), ML refers to a computer-based system that may be trained to find patterns among datasets, which can then be used to classify or predict various parameters and improve its performance by feeding new data [90]. Machine learning may be divided into supervised and unsupervised algorithms, of particular interest are the supervised groups, which are further sub-classified into (i) classification or pattern recognition, which is used to categorize samples into different groups, and (ii) regression algorithms, which are used to predict specific attributes or parameters such as chemometrics or intensities of sensory attributes $[90,93]$. While several different classification and regression algorithms exist, the use of artificial neural network (ANN) modeling has been widely researched due to its ability to find complex and non-linear relationships between the inputs and the outputs $[92,93]$. ANNs are ML models based on the function of the human brain [94-96]. In ANN, "neurons" (mathematical functions) are linked together similarly to neurons in the human brain, with weights randomly assigned to each neuron. Attached to this structure is the training and recall algorithm, which adjusts the weights assigned to each neuron until the desired output is achieved $[96,97]$. ANN's advantage is the ability to learn from a set of given data, the inputs or independent variables, and develop complex, non-linear relationships between these inputs and the dependent variables or targets with ease compared to traditional chemometric techniques such as partial least squares (PLS) or principal component analysis (PCA) $[5,92,93,98]$. For example, research by Summerson et al. [5] developed ANN models that accurately classified either berry (Model 1: $98.00 \%$ overall accuracy) or leaf (Model 2: $97.40 \%$ overall accuracy) NIR readings according to the different smoke treatments applied. Furthermore, several studies have demonstrated great success in predicting levels of smoke-derived volatile phenols and their glycoconjugates in grapes and wine using NIR spectroscopy and ANN modeling [6,88]. A study by Fuentes et al. [88] developed a model that accurately predicts levels of guaiacol glycoconjugates in berries as well as guaiacol and guaiacol glycoconjugates for seven different grapevine cultivars 
using NIR berry measurements between 700 and $1100 \mathrm{~nm}$. In further research, Summerson et al. [6] developed five different models that displayed high accuracy in predicting levels of volatile phenols and their glycoconjugates in Cabernet Sauvignon grapes and wine. The first three models were developed using NIR berry spectra taken one day after grapevine smoke exposure as inputs to predict levels of 10 volatile phenols and 18 glycoconjugates in grapes at either one day after smoke exposure (Model 1: $R=0.98 ; R^{2}=0.97$; $b=1$ ) or harvest (Model 2: $R=0.98 ; R^{2}=0.97 ; b=0.97$ ), as well as six volatile phenols and 17 glycoconjugates in the final wine (Model 3: $R=0.98 ; R^{2}=0.95 ; b=0.99$ ). The other two models used either must (Model 4: $R=0.99 ; R^{2}=0.99 ; b=1.00$ ) or wine (Model 5: $R=0.99$; $\left.R^{2}=0.97 ; b=0.97\right)$ NIR absorbance spectra to predict the levels of six volatile phenols and 17 glycoconjugates in the final wine. However, further research on these models is required to assess whether they can be used for other grape and wine varieties and winemaking techniques such as using different yeast strains and different durations of skin contact time during fermentation. In addition to this, research into the use of other ML techniques is also required to assess whether they provide better results. The models developed in both studies may offer grape growers and winemakers additional tools that could be used to accurately assess at near-real-time the levels of smoke-related compounds in grapes and/or wine, allowing them to make timely decisions around berry sampling, such as avoiding heavily contaminated grapes or sending them for further quantitative analysis, and winemaking practices to minimize levels of smoke compounds in the final wine, such as reducing skin contact time during fermentation, as well as potentially applying smoke taint amelioration techniques such as treatment with activated carbon [6]. In addition to this, the non-destructive nature of these techniques allows for repeated measurements.

In addition to the use of spectroscopic techniques for assessing grapevine smoke contamination and taint in grapes and wine, another rapid tool for assessment is being investigated using an electronic nose (e-nose). Electronic noses generally comprise gas sensors and a pattern recognition system that recognizes simple and complex odors [99-102]. These instruments have experienced significant development, with various e-noses available comprising different sensor types, data processing, pattern recognition systems, and/or functioning principles $[15,100]$. Furthermore, their applications range from assessing food quality, including meat and wine quality assessment, to environmental monitoring such as air quality assessment $[15,100,102]$. Recent research by Fuentes et al. [15] investigated using an e-nose to assess wines produced from different levels (densities) of smoke-affected grapes. The results from the e-nose were used as inputs to create five different ANN models: (i) a classification model with a high accuracy $(97 \%)$ in classifying wine samples according to the different smoke treatments, (ii) a regression model that accurately predicted levels of smoke compounds in grape berries one hour after smoke exposure $\left(R=0.98 ; R^{2}=0.95\right.$; $\mathrm{b}=0.97$ ), (iii) a regression model that accurately predicted levels of smoke compounds in grape berries at harvest $\left(R=0.99 ; R^{2}=0.97 ; b=0.96\right)$, (iv) a regression model that predicted levels of smoke compounds in wine with high accuracy $\left(R=0.99 ; R^{2}=0.98 ; b=0.98\right)$, and $(\mathrm{v})$ a regression model that accurately predicted consumer sensory responses using 12 wine descriptors $\left(R=0.98 ; R^{2}=0.96 ; b=0.97\right)$. In another study, Antolini et al. [103] investigated using an e-nose to assess grape berries for smoke contamination. Following smoke treatments, berries were peeled, and the pulp was separated from the skin. Samples of the skin and pulp were placed in glass vials and assessed. Their results found that the e-nose was capable of discriminating berry smoke contamination and may offer an additional tool for the early detection of smoke taint. These early studies demonstrate promising results for the use of e-noses for smoke taint detection.

New and emerging digital technologies, such as NIR spectroscopy and e-noses using machine learning and AI, have been developed with affordable instrumentation and user-friendly AI models and deployment methods [5,6,15,28,87,88,103]. For NIR, instruments using the required spectra resolution are more affordable and can even be operated using smartphones [104-106]. In the case of newly developed low-cost e-noses, grape growers and winemakers can be applied easily using AI models deployment on personal 
computers [15]. Other technologies that can be used, such as e-noses and e-tongues, are cost-prohibitive at the moment [107], and they have not been used for smoke taint research implementing AI.

Since these technologies have been recently developed, commercialization efforts are underway to offer viticultural and winemaking companies services in 2022. Implementing these technologies will provide near-real-time information on the classification of smoke taint into different levels and the actual estimation of smoke-related compounds and aroma profiles, making amelioration techniques more practical and potentially applied in the same wineries using micro-vinification immediately after harvest or small wine samples for testing.

Recent models based on AI and specifically using machine learning have been based on the estimation steps for chemometrics $[5,6,90]$, smoke-related compounds $[5,6]$, aroma profiles [15,103], and sensory information of final wines $[6,15,90,108-110]$, which give more information of changes at different stages and deal with the better understanding of intermediary processes while doing amelioration techniques at various stages (Tables 4 and 5). In this way, the AI models developed to offer further intermediary information rather than a direct AI model, which gives specific targets that can be considered a black box.

Table 5. Summary of the main grapevine phenological stages where there is a high risk of smoke taint and respective smoke compound measurement techniques.

\begin{tabular}{|c|c|c|c|c|c|}
\hline $\begin{array}{l}\text { Phenological } \\
\text { Stage }\end{array}$ & E-L Stage & Description & $\begin{array}{l}\text { Smoke Compounds } \\
\text { Measurements }\end{array}$ & $\begin{array}{l}\text { Amelioration } \\
\text { Strategy }\end{array}$ & Citation \\
\hline Veraison & 35 & $\begin{array}{l}\text { Berries color } \\
\text { and enlarge }\end{array}$ & \multirow{2}{*}{$\begin{array}{l}\text { High-performance liquid } \\
\text { chromatography (HPLC) }\end{array}$} & \multirow{4}{*}{ Refer to Table 4} & \multirow{4}{*}{$\begin{array}{l}{[2,5,6,9,15,59} \\
88,90,99-106]\end{array}$} \\
\hline Post-veraison & 36 & $\begin{array}{l}\text { Berries have } \\
\text { moderate sugar } \\
\text { content }\end{array}$ & & & \\
\hline & 37 & Berries not fully ripe & \multirow{2}{*}{$\begin{array}{l}\text { Near-infrared spectroscopy (NIR), } \\
\text { electronic nose (e-nose), and } \\
\text { artificial intelligence (AI) }\end{array}$} & & \\
\hline Harvest & 38 & $\begin{array}{l}\text { Berries ripe } \\
\text { for harvest }\end{array}$ & & & \\
\hline $\begin{array}{l}\text { Postharvest } \\
\text { processing }\end{array}$ & \multicolumn{2}{|c|}{ Description } & $\begin{array}{l}\text { Smoke Compounds } \\
\text { measurements }\end{array}$ & $\begin{array}{l}\text { Amelioration } \\
\text { strategy }\end{array}$ & Citation \\
\hline Winemaking & \multicolumn{2}{|c|}{$\begin{array}{l}\text { Involves micro- and industrial vinification } \\
\text { at all stages }\end{array}$} & $\begin{array}{l}\text { High-performance liquid } \\
\text { chromatography (HPLC) }\end{array}$ & \multirow[b]{2}{*}{ Refer to Table 4} & \multirow[b]{2}{*}{$\begin{array}{l}{[6,15,59,76,88,} \\
90,99-106]\end{array}$} \\
\hline Final product & Involves the w & efore and after bottling & $\begin{array}{l}\text { Near-infrared spectroscopy (NIR), } \\
\text { electronic nose (e-nose), and } \\
\text { artificial intelligence (AI) }\end{array}$ & & \\
\hline
\end{tabular}

\section{Conclusions}

Smoke contains a complex mixture of gases and volatile phenols that may affect grape berries' chemical composition and result in smoke-tainted wine. Uptake of smoke-derived volatile phenols may occur through grapevine leaves and berries, with the most sensitive period for berry uptake occurring between 7 days post-veraison and harvest. These volatile phenols are rapidly glycosylated and stored primarily in the skins of grape berries and the pulp. Traditional methods for smoke taint analysis are time-consuming, destructive, and require trained personnel to conduct them. Significant research into the use of spectroscopic techniques coupled with machine learning (ML) based on artificial neural networks (ANN) has been conducted to offer rapid, accurate, and non-destructive tools that can be used in-field to assess for grapevine smoke contamination and provide insight into the levels of volatile phenols and their glycoconjugates in grapes and wine. In addition to this, the use of e-noses has demonstrated promising results for smoke taint detection in wine and berries. These techniques may allow growers and winemakers to make timely decisions around berry sampling, winemaking practices such as reducing skin contact time during fermentation and potentially applying smoke taint mitigation techniques such as activated 
carbon treatment. Further research is required to assess the accuracy of ANNs developed on different grape and wine varieties as well as different winemaking techniques such as different yeast strains and fermentation time on skins and the use of other ML techniques to assess whether they provide more accurate results than ANNs.

Author Contributions: Project administration, S.F.; supervision, D.D.T., A.P. and S.F.; visualization, V.S., C.G.V., D.D.T., A.P. and S.F.; writing — original draft, V.S.; writing—review and editing, V.S., C.G.V., D.D.T., A.P. and S.F. All authors have read and agreed to the published version of the manuscript.

Funding: This research received no external funding.

Acknowledgments: This research was supported through the Australian Government Research Training Program Scholarship.

Conflicts of Interest: The authors declare no conflict of interest.

\section{References}

1. De Vries, C.; Mokwena, L.; Buica, A.; McKay, M. Determination of volatile phenol in Cabernet Sauvignon wines, made from smoke-affected grapes, by using HS-SPME GC-MS. S. Afr. J. Enol. Vitic. 2016, 37, 15-21. [CrossRef]

2. Hayasaka, Y.; Baldock, G.; Pardon, K.; Jeffery, D.; Herderich, M. Investigation into the formation of guaiacol conjugates in berries and leaves of grapevine Vitis vinifera L. cv. Cabernet Sauvignon using stable isotope tracers combined with HPLC-MS and MS/MS analysis. J. Agric. Food Chem. 2010, 58, 2076-2081. [CrossRef] [PubMed]

3. Kennison, K.; Wilkinson, K.; Williams, H.; Smith, J.; Gibberd, M. Smoke-derived taint in wine: Effect of postharvest smoke exposure of grapes on the chemical composition and sensory characteristics of wine. J. Agric. Food Chem. 2007, 55, 10897-10901. [CrossRef] [PubMed]

4. Ristic, R.; van der Hulst, L.; Capone, D.; Wilkinson, K. Impact of Bottle Aging on Smoke-Tainted Wines from Different Grape Cultivars. J. Agric. Food Chem. 2017, 65, 4146-4152. [CrossRef]

5. Summerson, V.; Gonzalez Viejo, C.; Szeto, C.; Wilkinson, K.L.; Torrico, D.D.; Pang, A.; Bei, R.D.; Fuentes, S. Classification of Smoke Contaminated Cabernet Sauvignon Berries and Leaves Based on Chemical Fingerprinting and Machine Learning Algorithms. Sensors 2020, 20, 5099. [CrossRef]

6. Summerson, V.; Viejo, C.G.; Torrico, D.D.; Pang, A.; Fuentes, S. Detection of smoke-derived compounds from bushfires in Cabernet-Sauvignon grapes, must, and wine using Near-Infrared spectroscopy and machine learning algorithms. OENO One 2020, 54, 1105-1119. [CrossRef]

7. Cain, N.; Hancock, F.; Rogers, P.; Downey, M. The effect of grape variety and smoking duration on the accumulation of smoke taint compounds in wine. Wine Vitic. J. 2013, 28, 48-49.

8. Kennison, K.; Ward, G.; Fisher, D. Key Information on Smoke Effect in Grapes and Wine: What Can Be done to Identify and Reduce Smoke Effect in Grape and Wine Production? Department of Agriculture and Food Western Australia. Western Australia Agriculture Authority. 2011. Available online: https://www.djdaxx.com/wp-content/uploads/smoke_effect_in_grapes_and_ wine.pdf (accessed on 10 October 2020).

9. Dungey, K.A.; Hayasaka, Y.; Wilkinson, K.L. Quantitative analysis of glycoconjugate precursors of guaiacol in smoke-affected grapes using liquid chromatography-tandem mass spectrometry based stable isotope dilution analysis. Food Chem. 2011, 126, 801-806. [CrossRef]

10. Noestheden, M.; Dennis, E.G.; Zandberg, W.F. Quantitating Volatile Phenols in Cabernet Franc Berries and Wine after On-Vine Exposure to Smoke from a Simulated Forest Fire. J. Agric. Food Chem. 2018, 66, 695-703. [CrossRef]

11. Kennison, K.; Gibberd, M.; Pollnitz, A.; Wilkinson, K. Smoke-Derived Taint in Wine: The Release of Smoke-Derived Volatile Phenols during Fermentation of Merlot Juice following Grapevine Exposure to Smoke. J. Agric. Food Chem. 2008, 56, 7379-7383. [CrossRef]

12. CSIRO; Australian Government Bureau of Meteorology. State of the Climate 2018. Available online: http://www.bom.gov.au/ state-of-the-climate/2018/State-of-the-Climate-2018.pdf (accessed on 10 October 2020).

13. Flannigan, M.D.; Krawchuk, M.A.; de Groot, W.J.; Wotton, B.M.; Gowman, L.M. Implications of changing climate for global wildland fire. Int. J. Wildland Fire 2009, 18, 483-507. [CrossRef]

14. Climate Council. This Is not Normal: Climate Change and Escalating Bushfire Risk; Climate Council Briefing Paper 2019. Available online: https://www.climatecouncil.org.au/wp-content/uploads/2019/11/bushfire-briefing-paper_18-november.pdf (accessed on 15 September 2020).

15. Fuentes, S.; Summerson, V.; Viejo, C.G.; Tongson, E.; Lipovetzky, N.; Wilkinson, K.L.; Szeto, C.; Unnithan, R.R. Assessment of Smoke Contamination in Grapevine Berries and Taint in Wines Due to Bushfires Using a Low-Cost E-Nose and an Artificial Intelligence Approach. Sensors 2020, 20, 5108. [CrossRef] [PubMed]

16. Noestheden, M.; Noyovitz, B.; Riordan-Short, S.; Dennis, E.G.; Zandberg, W.F. Smoke from simulated forest fire alters secondary metabolites in Vitis vinifera L. berries and wine. Planta 2018. [CrossRef] 
17. Collins, C.; Gao, H.; Wilkinson, K. An observational study into the recovery of grapevines (Vitis vinifera L.) following a bushfire. Am. J. Enol. Vitic. 2014, 65, 285-292. [CrossRef]

18. Kelly, D.; Zerihun, A.; Singh, D.; von Eckstaedt, C.V.; Gibberd, M.; Grice, K.; Downey, M. Exposure of grapes to smoke of vegetation with varying lignin composition and accretion of lignin derived putative smoke taint compounds in wine. Food Chem. 2012, 135, 787-798. [CrossRef] [PubMed]

19. Krstic, M.; Johnson, D.; Herderich, M. Review of smoke taint in wine: Smoke-derived volatile phenols and their glycosidic metabolites in grapes and vines as biomarkers for smoke exposure and their role in the sensory perception of smoke taint. Aust. J. Grape Wine Res. 2015, 21, 537-553. [CrossRef]

20. Sheppard, S.; Dhesi, M.; Eggers, N. Effect of Pre- and Postveraison Smoke Exposure on Guaiacol and 4-Methylguaiacol Concentration in Mature Grapes. Am. J. Enol. Vitic. 2009, 60, 98-103.

21. Bell, T.; Stephens, S.; Moritz, M. Short-term physiological effects of smoke on grapevine leaves. Int. J. Wildland Fire 2013, 22, 933-946. [CrossRef]

22. Noestheden, M.; Dennis, E.G.; Romero-Montalvo, E.; DiLabio, G.A.; Zandberg, W.F. Detailed characterization of glycosylated sensory-active volatile phenols in smoke-exposed grapes and wine. Food Chem. 2018, 259, 147-156. [CrossRef]

23. Parker, M.; Osidacz, P.; Baldock, G.A.; Hayasaka, Y.; Black, C.A.; Pardon, K.H.; Jeffery, D.W.; Geue, J.P.; Herderich, M.J.; Francis, I.L. Contribution of several volatile phenols and their glycoconjugates to smoke-related sensory properties of red wine. J. Agric. Food Chem. 2012, 60, 2629-2637. [CrossRef]

24. Härtl, K.; Huang, F.-C.; Giri, A.P.; Franz-Oberdorf, K.; Frotscher, J.; Shao, Y.; Hoffmann, T.; Schwab, W. Glucosylation of SmokeDerived Volatiles in Grapevine (Vitis vinifera) is Catalyzed by a Promiscuous Resveratrol/Guaiacol Glucosyltransferase. J. Agric. Food Chem. 2017, 65, 5681-5689. [CrossRef]

25. Ristic, R.; Boss, P.; Wilkinson, K. Influence of Fruit Maturity at Harvest on the Intensity of Smoke Taint in Wine. Molecules 2015, 20, 8913-8927. [CrossRef]

26. Singh, D.; Chong, H.; Pitt, K.; Cleary, M.; Dokoozlian, N.; Downey, M. Guaiacol and 4-methylguaiacol accumulate in wines made from smoke-affected fruit because of hydrolysis of their conjugates. Aust. J. Grape Wine Res. 2011, 17, S13-S21. [CrossRef]

27. Singh, D.; Zerihun, A.; Kelly, D.; Cain, N.M.; Nankervis, P.; Downey, M.O. A GC-MS Based Analytical Method for Detection of Smoke Taint Associated Phenols in Smoke Affected Wines. Curr. Bioact. Compd. 2012, 8, 190-199. [CrossRef]

28. Fuentes, S.; Tongson, E. Advances in smoke contamination detection systems for grapevine canopies and berries. Wine Vitic. J. 2017, 32, 36 .

29. Fudge, A.; Ristic, R.; Wollan, D.; Wilkinson, K. Amelioration of smoke taint in wine by reverse osmosis and solid phase adsorption. Aust. J. Grape Wine Res. 2011, 17, S41-S48. [CrossRef]

30. Noestheden, M.; Thiessen, K.; Dennis, E.G.; Tiet, B.; Zandberg, W.F. Quantitating Organoleptic Volatile Phenols in Smoke-Exposed Vitis vinifera Berries. J. Agric. Food Chem. 2017, 65, 8418-8425. [CrossRef]

31. Whiting, J.; Krstic, M. Understanding the Sensitivity to Timing and Management Options to Mitigate the Negative Impacts of Bush Fire Smoke on Grape and Wine Quality-Scoping Study; Department of Primary Industries: Knoxfield, VIC, Australia, 2007.

32. Department of Primary Industries. Impacts of Smoke on Grapes and Wine in Victoria; Department of Primary Industries: Mildura, VIC, Australia, 2009; Available online: http://wine.wsu.edu/research-extension/files/2012/10/DPI-fact-sheet_Impacts-ofsmoke-on-grapes-and-wine-in-Victoria_final.pdf (accessed on 10 October 2020).

33. Claughton, D.; Jeffery, C.; Pritchard, M.; Hough, C.; Wheaton, C. Wine Industry's 'Black Summer' as Cost of Smoke Taint, Burnt Vineyards, and Lost Sales Add Up. ABC News. 28 February 2020. Available online: https://www.abc.net.au/news/rural/2020-0 2-28/fire-and-smoke-costs-wine-industry-40-million-dollars/11972450 (accessed on 9 September 2020).

34. Kennison, K.; Wilkinson, K.; Pollnitz, A.; Williams, H.; Gibberd, M. Effect of timing and duration of grapevine exposure to smoke on the composition and sensory properties of wine. Aust. J. Grape Wine Res. 2009, 15, 228-237. [CrossRef]

35. Ristic, R.; Fudge, A.; Pinchbeck, K.; De Bei, R.; Fuentes, S.; Hayasaka, Y.; Tyerman, S.; Wilkinson, K. Impact of grapevine exposure to smoke on vine physiology and the composition and sensory properties of wine. Theor. Exp. Plant Physiol. 2016, 28, 67-83. [CrossRef]

36. Wang, H.; Chambers, E., IV. Sensory characteristics of various concentrations of phenolic compounds potentially associated with smoked aroma in foods. Molecules 2018, 23, 780. [CrossRef] [PubMed]

37. Kostyra, E.; Baryłko-Pikielna, N. Volatiles composition and flavour profile identity of smoke flavourings. Food Qual. Prefer. 2006, 17, 85-95. [CrossRef]

38. Nawawi, D.S.; Syafii, W.; Tomoda, I.; Uchida, Y.; Akiyama, T.; Yokoyama, T.; Matsumoto, Y. Characteristics and Reactivity of Lignin in Acacia and Eucalyptus Woods. J. Wood Chem. Technol. 2017, 37, 273-282. [CrossRef]

39. De Vries, C.; Buica, A.; McKay, J.B.M. The impact of smoke from vegetation fires on sensory characteristics of cabernet sauvignon wines made from affected grapes. S. Afr. J. Enol. Vitic. 2016, 37, 22-30. [CrossRef]

40. Favell, J.W.; Noestheden, M.; Lyons, S.-M.; Zandberg, W.F. Development and evaluation of a vineyard-based strategy to mitigate smoke-taint in wine grapes. J. Agric. Food Chem. 2019, 67, 14137-14142. [CrossRef] [PubMed]

41. Härtl, K.; Schwab, W. Smoke Taint in Wine-How smoke-derived volatiles accumulate in grapevines. Wines Vines 2018, 99/02, 62-64.

42. Pollnitz, A.P.; Pardon, K.H.; Sykes, M.; Sefton, M.A. The effects of sample preparation and gas chromatograph injection techniques on the accuracy of measuring guaiacol, 4-methylguaiacol and other volatile oak compounds in oak extracts by stable isotope dilution analyses. J. Agric. Food Chem. 2004, 52, 3244-3252. [CrossRef] 
43. Allen, D.; Bui, A.D.; Cain, N.; Rose, G.; Downey, M. Analysis of free and bound phenolics in wine and grapes by GC-MS after automated SPE. Anal. Bioanal. Chem. 2013, 405, 9869-9877. [CrossRef] [PubMed]

44. Simos, C. The implications of smoke taint and management practices. Aust. Vitic. Jan/Feb 2008, 12, 77-80.

45. Hayasaka, Y.; Baldock, G.; Parker, M.; Pardon, K.; Black, C.; Herderich, M.; Jeffery, D. Glycosylation of smoke-derived volatile phenols in grapes as a consequence of grapevine exposure to bushfire smoke. J. Agric. Food Chem. 2010, 58, 10989-10998. [CrossRef]

46. Kelly, D.; Zerihun, A. The Effect of Phenol Composition on the Sensory Profile of Smoke Affected Wines. Molecules 2015, 20, 9536-9549. [CrossRef]

47. Kennison, K. Bushfire Generated Smoke Taint in Grapes and Wine. Final Report to Grape and Wine Research and Development Corporation; RD 05/02-3; Department of Agriculture and Food Western Australia: Perth, WA, Australia, 2009.

48. Boidron, J.-N.; Chatonnet, P.; Pons, M. Influence du bois sur certaines substances odorantes des vins. OENO One 1988, 22, 275-294. [CrossRef]

49. Simpson, R.; Amon, J.; Daw, A. Off-flavour in wine caused by guaiacol [1986]. Food Technol. Aust. 2013, $38,31-33$.

50. Pardo-Garcia, A.; Wilkinson, K.; Culbert, J.; Lloyd, N.; Alonso, G.L.; Salinas, M.R. Accumulation of Glycoconjugates of 3-Methyl4-hydroxyoctanoic Acid in Fruits, Leaves, and Shoots of Vitis vinifera cv. Monastrell following Foliar Applications of Oak Extract or Oak Lactone. J. Agric. Food Chem. 2015, 63, 4533-4538. [CrossRef] [PubMed]

51. Pardo-Garcia, A.; Wilkinson, K.; Culbert, J.; Lloyd, N.; Alonso, G.; Salinas, M.R. Accumulation of guaiacol glycoconjugates in fruit, leaves and shoots of Vitis vinifera cv. Monastrell following foliar applications of guaiacol or oak extract to grapevines. Food Chem. 2017, 217, 782-789. [CrossRef]

52. The Australian Wine Research Institute. Smoke Taint-Entry into Grapes and Vineyard Risk Factors. 2015. Available online: https: / / www.awri.com.au/wp-content/uploads/2012/04/smoke-taint-entry-into-grapes-and-vineyard-risk-factors.pdf (accessed on 15 September 2020).

53. Hoj, P.; Pretorius, I.; Blair, R. Investigations Conducted into the Nature and Amelioration of Taints in Grapes and Wine, Caused by Smoke Resulting from Bushfires. In The Australian Wine Research Institute Annual Report 2003; The Australian Wine Research Institute: Adelaide, SA, Australia, 2003; pp. 37-39.

54. Beattie, G.A.; Seibel, J.R. Uptake and localization of gaseous phenol and p-cresol in plant leaves. Chemosphere 2007, 68, 528-536. [CrossRef] [PubMed]

55. Martínez-Gil, A.; Garde-Cerdán, T.; Martínez, L.; Alonso, G.; Salinas, M.R. Effect of Oak Extract Application to Verdejo Grapevines on Grape and Wine Aroma. J. Agric. Food Chem. 2011, 59, 3253-3263. [CrossRef]

56. Martínez-Gil, A.; Garde-Cerdán, T.; Zalacain, A.; Pardo-García, A.; Salinas, M.R. Applications of an oak extract on Petit Verdot grapevines. Influence on grape and wine volatile compounds. Food Chem. 2012, 132, 1836-1845. [CrossRef]

57. Pardo-García, A.I.; de la Hoz, K.S.; Zalacain, A.; Alonso, G.L.; Salinas, M.R. Effect of vine foliar treatments on the varietal aroma of Monastrell wines. Food Chem. 2014, 163, 258-266. [CrossRef]

58. Australian Wine Rearch Institute. Annual Report 2003; Australian Wine Rearch Institute: Adelaide, SA, Australia, 2003.

59. Kennison, K.; Wilkinson, K.; Pollnitz, A.; Williams, H.; Gibberd, M. Effect of smoke application to field-grown Merlot grapevines at key phenological growth stages on wine sensory and chemical properties. Aust. J. Grape Wine Res. 2011, 17, 5-12. [CrossRef]

60. Brodison, K. Bulletin 4847: Effect of Smoke in Grape and Wine Production; Department of Agriculture and Food Western Australia: Perth, WA, Australia, 2013. Available online: http:/ / citeseerx.ist.psu.edu/viewdoc/download;jsessionid=7DCE37912829907FD8 A627BFB05F4822?doi=10.1.1.392.6887\&rep=rep1\&type=pdf (accessed on 10 October 2020).

61. Calder, J.; Lifferth, G.; Moritz, M.; St Clair, S. Physiological Effects of Smoke Exposure on Deciduous and Conifer Tree Species. Int. J. For. Res. 2010, 2010, 1-7. [CrossRef]

62. Gilbert, M.; Ripley, B.; van Staden, J. The effect of smoke on the photosynthetic gas exchange of Chrysanthemoides monilifera. $S$. Afr. J. Bot. 2002, 68, 525-531. [CrossRef]

63. During, H. Photochemical and non-photochemical responses of glasshouse-grown grape to combined light and water stress. Vitis 1998, 37, 1-4.

64. Sepúlveda, G.; Kliewer, W.M.; Ryugo, K. Effect of high temperature on grapevines (Vitis vinifera L.). I. Translocation of 14Cphotosynthates. Am. J. Enol. Vitic. 1986, 37, 13-19.

65. Hayasaka, Y.; Dungey, K.; Baldock, G.; Kennison, K.; Wilkinson, K. Identification of a $\beta$-d-glucopyranoside precursor to guaiacol in grape juice following grapevine exposure to smoke. Anal. Chim. Acta 2010, 660, 143-148. [CrossRef] [PubMed]

66. Martínez-Gil, A.; Angenieux, M.; Pardo-García, A.; Alonso, G.; Ojeda, H.; Salinas, R. Glycosidic aroma precursors of Syrah and Chardonnay grapes after an oak extract application to the grapevines. Food Chem. 2013, 138, 956-965. [CrossRef]

67. Mayr, C.M.; Parker, M.; Baldock, G.A.; Black, C.A.; Pardon, K.H.; Williamson, P.O.; Herderich, M.J.; Francis, I.L. Determination of the Importance of In-Mouth Release of Volatile Phenol Glycoconjugates to the Flavor of Smoke-Tainted Wines. J. Agric. Food Chem. 2014, 62, 2327-2336. [CrossRef] [PubMed]

68. Ristic, R.; Osidacz, P.; Pinchbeck, K.; Hayasaka, Y.; Fudge, A.; Wilkinson, K. The effect of winemaking techniques on the intensity of smoke taint in wine. Aust. J. Grape Wine Res. 2011, 17, S29-S40. [CrossRef]

69. Otero, R.R.C.; Iranzo, J.F.U.; Briones-Perez, A.I.; Potgieter, N.; Villena, M.A.; Pretorius, I.S.; Rensburg, P.V. Characterization of the $\beta$-Glucosidase Activity Produced by Enological Strains of Non-Saccharomyces Yeasts. J. Food Sci. 2003, 68, 2564-2569. [CrossRef] 
70. Government of Western Australia: Department of Primary Industries and Regional Development. Management of Grapes and Wine after Smoke Events. 2018. Available online: https://www.agric.wa.gov.au/fire/management-grapes-and-wine-aftersmoke-events (accessed on 25 August 2020).

71. van der Hulst, L.; Munguia, P.; Culbert, J.A.; Ford, C.M.; Burton, R.A.; Wilkinson, K.L. Accumulation of volatile phenol glycoconjugates in grapes following grapevine exposure to smoke and potential mitigation of smoke taint by foliar application of kaolin. Planta 2019, 249, 941-952. [CrossRef]

72. Fudge, A.; Schiettecatte, M.; Ristic, R.; Hayasaka, Y.; Wilkinson, K. Amelioration of smoke taint in wine by treatment with commercial fining agents. Aust. J. Grape Wine Res. 2012, 18, 302-307. [CrossRef]

73. Ulrich, T. When the Smoke Cleared: California Winemakers Face Tough Pre-Bottling Decisions for 2008 Wines. Available online: https: / / winesvinesanalytics.com/sections/printout_article.cfm?article=feature\&content=65507 (accessed on 25 October 2020).

74. The Australian Wine Research Institute. Smoke Taint Analysis. Available online: https://www.awri.com.au/wp-content/ uploads/awri_smoke_analysis_faq.pdf (accessed on 25 October 2020).

75. Fudge, A.; Wilkinson, K.; Ristic, R.; Cozzolino, D. Classification of smoke tainted wines using mid-infrared spectroscopy and chemometrics. J. Agric. Food Chem. 2012, 60, 52-59. [CrossRef] [PubMed]

76. Fudge, A.; Wilkinson, K.; Ristic, R.; Cozzolino, D. Synchronous two-dimensional MIR correlation spectroscopy (2D-COS) as a novel method for screening smoke tainted wine. Food Chem. 2013, 139, 115-119. [CrossRef]

77. Barbin, D.F.; De Souza Madureira Felicio, A.L.; Sun, D.-W.; Nixdorf, S.L.; Hirooka, E.Y. Application of infrared spectral techniques on quality and compositional attributes of coffee: An overview. Food Res. Int. 2014, 61, 23-32. [CrossRef]

78. dos Santos, C.T.; Lopo, M.; Ricardo, N.; Lopes, J. A Review on the Applications of Portable Near-Infrared Spectrometers in the Agro-Food Industry. Appl. Spectrosc. 2013, 67, 1215-1233. [CrossRef]

79. Urraca, R.; Sanz-Garcia, A.; Tardaguila, J.; Diago, M.P. Estimation of total soluble solids in grape berries using a handheld NIR spectrometer under field conditions. J. Sci. Food Agric. 2016, 96, 3007-3016. [CrossRef]

80. Hall, A. Remote Sensing Applications for Viticultural Terroir Analysis. Elements 2018, 14, 185-190. [CrossRef]

81. Fuentes, S.; De Bei, R.; Pech, J.; Tyerman, S. Computational water stress indices obtained from thermal image analysis of grapevine canopies. Irrig. Sci. 2012, 30, 523-536. [CrossRef]

82. Poblete-Echeverría, C.; Sepulveda-Reyes, D.; Ortega-Farias, S.; Zuñiga, M.; Fuentes, S. Plant water stress detection based on aerial and terrestrial infrared thermography: A study case from vineyard and olive orchard. In Proceedings of the XXIX International Horticultural Congress on Horticulture: Sustaining Lives, Livelihoods and Landscapes (IHC2014), Brisbane, QLD, Australia, 17-22 August 2014; 1112, pp. 141-146.

83. Poblete-Echeverría, C.; Ortega-Farías, S.; Zuñiga, M.; Lobos, G.; Romero, S.; Estrada, F.; Fuentes, S. Use of infrared thermography on canopies as indicator of water stress in 'Arbequina'olive orchards. In Proceedings of the VII International Symposium on Olive Growing, San Juan, Argentina, 25-29 September 2012; 1057, pp. 399-403.

84. Pou, A.; Diago, M.P.; Medrano, H.; Baluja, J.; Tardaguila, J. Validation of thermal indices for water status identification in grapevine. Agric. Water Manag. 2014, 134, 60-72. [CrossRef]

85. Jackson, R.D.; Idso, S.; Reginato, R.; Pinter, P., Jr. Canopy temperature as a crop water stress indicator. Water Resour. Res. 1981, 17, 1133-1138. [CrossRef]

86. Gontia, N.; Tiwari, K. Development of crop water stress index of wheat crop for scheduling irrigation using infrared thermometry. Agric. Water Manag. 2008, 95, 1144-1152. [CrossRef]

87. Fuentes, S.; Tongson, E.; Summerson, V.; Viejo, C.G. Advances in Artificial Intelligence to Assess Smoke Contamination in Grapevines and Taint in Wines Due to Increased Bushfire Events. Wine Vitic. J. 2020, 35, $26-29$.

88. Fuentes, S.; Tongson, E.J.; De Bei, R.; Gonzalez Viejo, C.; Ristic, R.; Tyerman, S.; Wilkinson, K. Non-Invasive Tools to Detect Smoke Contamination in Grapevine Canopies, Berries and Wine: A Remote Sensing and Machine Learning Modeling Approach. Sensors 2019, 19, 3335. [CrossRef]

89. Dolatabadi, Z.; Rad, A.H.E.; Farzaneh, V.; Feizabad, S.H.A.; Estiri, S.H.; Bakhshabadi, H. Modeling of the lycopene extraction from tomato pulps. Food Chem. 2016, 190, 968-973. [CrossRef] [PubMed]

90. Viejo, C.G.; Torrico, D.D.; Dunshea, F.R.; Fuentes, S. Emerging technologies based on artificial intelligence to assess the quality and consumer preference of beverages. Beverages 2019, 5, 62. [CrossRef]

91. Gumus, Z.P.; Ertas, H.; Yasar, E.; Gumus, O. Classification of olive oils using chromatography, principal component analysis and artificial neural network modelling. J. Food Meas. Charact. 2018, 12, 1325-1333. [CrossRef]

92. Pero, M.; Askari, G.; Skåra, T.; Skipnes, D.; Kiani, H. Change in the color of heat-treated, vacuum-packed broccoli stems and florets during storage: Effects of process conditions and modeling by an artificial neural network. J. Sci. Food Agric. 2018, 98, 4151-4159. [CrossRef] [PubMed]

93. Gonzalez Viejo, C.; Torrico, D.D.; Dunshea, F.R.; Fuentes, S. Development of artificial neural network models to assess beer acceptability based on sensory properties using a robotic pourer: A comparative model approach to achieve an artificial intelligence system. Beverages 2019, 5, 33. [CrossRef]

94. Gutierrez, S.; Tardaguila, J.; Fernandez-Novales, J.; Diago, M.P. Support vector machine and artificial neural network models for the classification of grapevine varieties using a portable NIR spectrophotometer. PLoS ONE 2015, 10, e0143197. [CrossRef] [PubMed] 
95. Pralle, R.; Weigel, K.; White, H. Predicting blood $\beta$-hydroxybutyrate using milk Fourier transform infrared spectrum, milk composition, and producer-reported variables with multiple linear regression, partial least squares regression, and artificial neural network. J. Dairy Sci. 2018, 101, 4378-4387. [CrossRef]

96. Tan, J.; Kerr, W.L. Determining degree of roasting in cocoa beans by artificial neural network (ANN)-based electronic nose system and gas chromatography/mass spectrometry (GC/MS). J. Sci. Food Agric. 2018, 98, 3851-3859. [CrossRef]

97. Shanmuganathan, S.; Samarasinghe, S. Artificial Neural Network Modelling; Springer: Cham, Switzerland, 2016.

98. Chandraratne, M.; Kulasiri, D.; Samarasinghe, S. Classification of lamb carcass using machine vision: Comparison of statistical and neural network analyses. J. Food Eng. 2007, 82, 26-34. [CrossRef]

99. Carmel, L.; Levy, S.; Lancet, D.; Harel, D. A feature extraction method for chemical sensors in electronic noses. Sens. Actuators B Chem. 2003, 93, 67-76. [CrossRef]

100. Cipriano, D.; Capelli, L. Evolution of electronic noses from research objects to engineered environmental odour monitoring systems: A review of standardization approaches. Biosensors 2019, 9, 75. [CrossRef]

101. Hines, E.; Llobet, E.; Gardner, J. Electronic noses: A review of signal processing techniques. IEE Proc. Circuits Devices Syst. 1999, 146, 297-310. [CrossRef]

102. Li, W.; Leung, H.; Kwan, C.; Linnell, B.R. E-nose vapor identification based on Dempster-Shafer fusion of multiple classifiers. IEEE Trans. Instrum. Meas. 2008, 57, 2273-2282. [CrossRef]

103. Antolini, A.; Forniti, R.; Modesti, M.; Bellincontro, A.; Catelli, C.; Mencarelli, F. First Application of Ozone Postharvest Fumigation to Remove Smoke Taint from Grapes. Ozone Sci. Eng. 2020, 1-9. [CrossRef]

104. Chapman, J.; Gangadoo, S.; Truong, V.K.; Cozzolino, D. Spectroscopic approaches for rapid beer and wine analysis. Curr. Opin. Food Sci. 2019, 28, 67-73. [CrossRef]

105. Sorak, D.; Herberholz, L.; Iwascek, S.; Altinpinar, S.; Pfeifer, F.; Siesler, H.W. New developments and applications of handheld Raman, mid-infrared, and near-infrared spectrometers. Appl. Spectrosc. Rev. 2012, 47, 83-115. [CrossRef]

106. O'Brien, N.A.; Hulse, C.A.; Friedrich, D.M.; Van Milligen, F.J.; von Gunten, M.K.; Pfeifer, F.; Siesler, H.W. Miniature near-infrared (NIR) spectrometer engine for handheld applications. In Proceedings of the Next-Generation Spectroscopic Technologies V, Baltimore, MD, USA, 23-24 April 2012; p. 837404.

107. Gardner, J.W.; Bartlett, P.N. A brief history of electronic noses. Sens. Actuators B Chem. 1994, 18, 210-211. [CrossRef]

108. Fuentes, S.; Tongson, E.; Torrico, D.D.; Gonzalez Viejo, C. Modeling Pinot Noir Aroma Profiles Based on Weather and Water Management Information Using Machine Learning Algorithms: A Vertical Vintage Analysis Using Artificial Intelligence. Foods 2020, 9, 33. [CrossRef]

109. Fuentes, S.; Torrico, D.D.; Tongson, E.; Gonzalez Viejo, C. Machine learning modeling of wine sensory profiles and color of vertical vintages of Pinot Noir based on chemical fingerprinting, weather and management data. Sensors 2020, 20, 3618. [CrossRef] [PubMed]

110. Fuentes, S.; Tongson, E.; Chen, J.; Gonzalez Viejo, C. A Digital Approach to Evaluate the Effect of Berry Cell Death on Pinot Noir Wines' Quality Traits and Sensory Profiles Using Non-Destructive Near-Infrared Spectroscopy. Beverages 2020, 6, 39. [CrossRef] 